\title{
Grossly carious mandibular first molar having supplemental root managed exodontically: A rarity reported
}

\author{
Ashvini Vadane ${ }^{1, *}$, Amit Sangle $^{2}$, Nashrah Sawant ${ }^{3}$ \\ ${ }^{1}$ Senior Lecturer, ${ }^{2}$ Professor, ${ }^{3}$ UG Student, Dept. of Oral and Maxillofacial Surgery, M.A. Rangoonwala College of Dental Sciences and \\ Research Centre, Pune, Maharashtra, India \\ *Corresponding Author: Ashvini Vadane \\ Email: drashvinivadane@gmail.com
}

\begin{abstract}
The mandibular first molar tooth commonly has two well-defined roots. But, sometimes the appearance and number of roots show variations. The prevalence of supernumerary root associated with mandibular molar is less than $5 \%$ in Asian populations and the most common variant is the mandibular first molar with the presence of supernumerary roots distolingually. ${ }^{1}$

The present article reports a case in which drashvinivadane@gmail.com supplemental root is present mesiolingually associated with mandibular first molar. Hence, this is the rarest entity. This case was reported in the department of Oral and Maxillofacial Surgery of M.A. Rangoonwala College of Dental Sciences and Research Centre, Pune and its extraction was performed.
\end{abstract}

Keywords: Supplemental root, Additional root, Mandibular first molar, Radix entomolaris, Extraction.

\section{Case Report}

A 48 years old male patient visited department of oral and maxillofacial surgery of our college with the chief complaint of pain in the lower left back teeth region of jaw since 10 days. The pain was thobbing in nature, constantly present and was restricted to that region only. On clinical examination, it is noted that there was grossly carious mandibular left first molar in the patients' jaw. Radiographic examination was adviced and intra-oral periapical view revealed carious mandibular left first molar. Tooth was grossly carious and it had lost all its walls. Hence, it was diagnosed as "Chronic periodontitis with mandibular left first molar" and treatment plan adviced was "extraction". The intra-oral periapical view radiograph revealed the presence of additional root with mandibular left first molar what literature supports as a very rare entity. Fig. 1 describes the radiographic findings. Extraction of mandibular left first molar was performed under left side inferior nerve block supplemented with lingual and long buccal nerve block. There was presence of three roots associated with this molar tooth as shown in Fig. 2. The presence of 3 roots associated with mandibular first molar is the very rare entity and found in less than $5 \%$ of Asian population. ${ }^{1}$ And the most common variant is that in which additional root is present distolingually. ${ }^{1}$ In this case supplemental root is present mesiolingually. Hence this article describes a rare case.

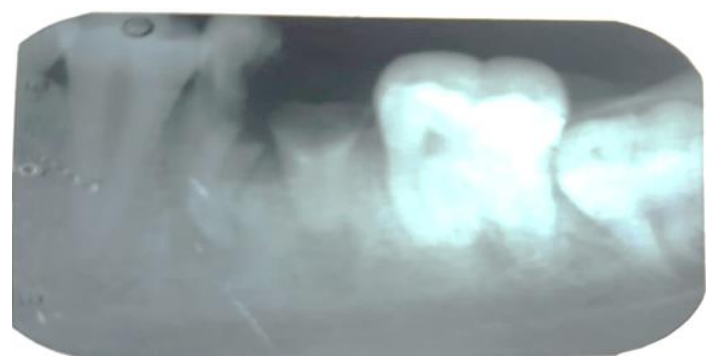

Fig. 1: IOPA revealing grossly carious three-rooted mandibular first molar

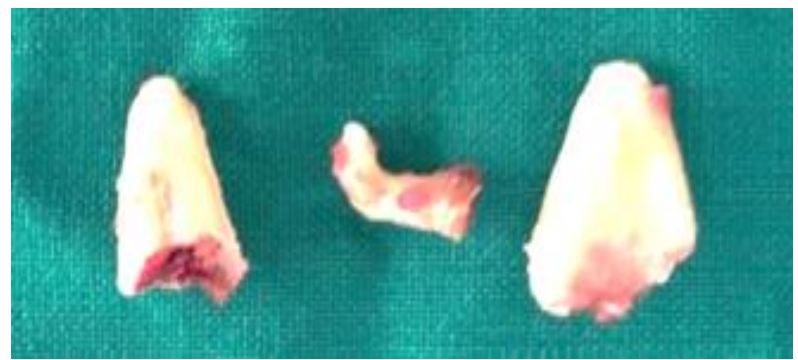

Fig. 2: Picture showing extracted 3 roots of mandibular first molar

\section{Discussion}

Proper knowledge of tooth morphology and number of roots is essential for every dentist and for anthropologic significance. Typically, the mandibular first molar has two roots. However, in some cases, the morphology and number of roots of the mandibular first molar tooth show variations. "Radix entomolaris" is the presence of supernumerary roots distolingually and this type is the major variant of mandibular first molar tooth with additional roots. ${ }^{1,10}$

Some authors consider that the anatomical variant of radix entomolaris is a genetic trait and it is not a developmental anomaly. ${ }^{1}$ The additional root with mandibular first molar is most commonly found distolingually present either in the form of short conical extension or a full-length root. ${ }^{1,2}$ In this reported case, the additional root is present mesiolingually which is very rarely present.

Carabelli had described this variant for the first time. Alexandersen and Carlsen had stated classification of "radix entomolaris" based on the location of its cervical part. This classification has described 4 types, i.e., "A", "B", "C" and "AC", which are as follows: 15

1. Type "A": Distally located cervical part of the radix entomolaris with two normal root components.

2. Type "B": Distally located cervical part of the radix 
entomolaris with one normal distal root components.

3. Type "C": Mesially located cervical part.

4. Type "AC": Central location of supplemental root between the distal and mesial roots.

The supplemental root associated with mandibular first molar tooth is noticed in about 3\% Africans, 3.4 -4.2\% of Caucasians whereas its prevalence is in less than $5 \%$ cases of Indians and higher than 5\% in Mongolian traits. ${ }^{2}$

This article reports a case in which additional root is present mesiolingually associated with mandibular first molar. Hence, this is the rarest entity. This case was reported in the department of Oral and Maxillofacial Surgery of M.A. Rangoonwala College of Dental Sciences and Research Centre, Pune and its extraction was performed.

\section{References}

1. Mothanna Alrahabi. Clinical management of a mandibular first molar with supernumerary distal root (radix entomolaris). $J$ Taibah Univ Med Sci 2014;9(1):81-84.

2. Vinay Kumar Bhardwaj. Additional Root in the Mandibular First Molar - A Rare Case Report. J Dent Health, Oral Disord Ther 2016;5(4):00162.

3. Bharath Parthasarathy, Manje Gowda, Sridhara K.S., Rajeev Subbaraya. Four canalled and three rooted mandibular first molar (Radix Entomolaris) -- Report of 2 Cases. J Dent Sci Res 2(2):1-5.

4. H Colak, E Ozcan, MM Hamidi. Prevalence of three-rooted mandibular permanent first molars among the Turkish population. Niger J Clin Pract 2012;15(3).

5. Clarissa Teles Rodrigues, Christiano de Oliveira - Santos, Norberti Bernardineli, Marco Antonio Hungaro Duarte, Clovis Monteiro Bramante, Paloma Gagliardi Minotti- Bonfante, Ronald Ordinola- Zapata. Prevalence and morphometric analysis of three-rooted mandibular first molars in a Brazilian subpopulation. J Appl Oral Sci 2016;24(5).

6. Mahajan, P., \& Mahajan, A. Supplemental root in a mandibular first molar: a rarity. Clin Pract 2011;1(1):e10.
7. Shivani Sachdeva, Mangesh B. Phadnaik. Three- rooted mandibular first molar: A consideration in periodontal therapy. Journal of Indian Society of Periodontology. 2012;16(2):286289.

8. Jose Antonio Brufato Ferraz, Jesus Djalma Pecora. ThreeRooted Mandibular Molars in Patients of Mongolian, Caucasian and Negro Origin. Braz Dent J 1992;3(2):113-117.

9. Mrunal Manohar Shinde, Sharad Basavraj Kamat, Rutuja Vijay Chopade. Bilateral Three Rooted Mandibular Premolars and Four Rooted Mandibular First and Second Molar: A Rare Anatomical Variant. J Clin Diagn Res 2016;10(10): ZD05ZD06.

10. Ming-Gene Tu. Detection of Permanent Three-rooted Mandibular First Molars by Cone-Beam Computed Tomography Imaging in Taiwanese Individuals. J Endod 2009;35:503-507.

11. Bhavana Vankayala. Sch J Dent Sci 2015;2(2A):30-131

12. Nagaveni N B, Manoharan M, Yadav S, Poornima P. Single rooted, single canalled mandibular first molar in association with multiple anomalies: Report of a rarest case with literature review. Niger J Exp Clin Biosci 2015;3:59-63.

13. Neeraja Ramamurthy, Ila Srinivasan. Bilateral three-rooted primary lower molars. Indian J Dent Res 2012;23:700.

14. Wadekar SI, Shah DY, Shah JR, Gathani KM. Endodontic Management of a Three-rooted Mandibular First Premolar associated with Taurodontis. J Oper Dent Endod 2016;(2):9092.

15. Diana John. Endodontic Management of a Mandibular First Molar with Radix Entomolaris --- A Case Report. IOSR JDMS 2016;15(8):21-24.

How to cite this article: Vadane A, Sangle A, Sawant N. Grossly carious mandibular first molar having supplemental root managed exodontically: A rarity reported. Int Dent J Student's Res. 2018;6(4):77-78. 